\title{
General problems of questioning research
}

\author{
Hans van der Meij \\ University of Twente, Department of Education, PO Box 217, 7500 AE Enschede, The Netherlands
}

Received February 23, 1991/Accepted May 7, 1991

Summary. This paper outlines certain minimum conditions for setting up experimental research on questioning. A discussion is given of the problems involved in using the same kinds of question as in natural interactions, creating a naturalistic exchange between questioner and respondent, and enabling people to use other inquiry strategies besides questioning. It is argued that these issues merit attention not only because of methodological concerns, but also because they are likely to lead to important insights about questioning.

\section{Introduction}

It takes skill and motivation to ask a question. First, a person who generates a question must experience perplexity and feel compelled to find things out. Second, expressing the question rightly is a difficult communicative task and must be handled carefully in order to avoid a painful social encounter. Third, the person must reflect upon the success of the question-asking strategy and the improvements that might be made in future. In short, what is sometimes considered a common part of a person's behavioral repertoire is really a most remarkable achievement. Asking a question is an expression of will, of effort, of courage, of committment, of skill, of kowledge, and of lack of knowledge (cf. Dillon, 1990).

Researchers have long been intrigued by what happens when someone asks a question. They generally have found the matter a difficult one to investigate. This paper therefore discusses some of the problems of research, outlining certain methodological minimum conditions for setting up experimental research. Most researchers try to create an experimental situation that is in a sense a proxy to a real context of inquiry. In doing so they are confronted with at least the following issues: the questions asked in the experiment should resemble the questions asked in reality; the exchange between questioner and respondent should be realistic, and question-asking should be one of many ways of gaining information. Each of these issues will be discussed below.

\section{Using the same kinds of question}

It is critically important to study the same kinds of question in the experiment as are found in a natural situation. Experiments that use a question-selection procedure (a method in which subjects select their questions from a prearranged set instead of generating them) should therefore use questions found in the natural setting. The importance of this simple rule of thumb can be illustrated by the research of Snyder (Snyder \& Swann, 1978; Snyder, 1981). In their research Snyder and his colleagues found that people (i.e., lay interviewers) tend to search for information that confirms their beliefs. Trope and Bassok (1983) criticized this finding, arguing that the list of questions from which the subjects selected their questions did not reflect the kinds of question people would normally generate for an interview. With a new list, based on questions asked in real interviews, they found question-asking to be diagnostic rather than confirmatory. There is also other evidence of the troublesome nature of the selection procedure. For example, when I compared question selection with question production in the same experiment, I found little correspondence on matters such as frequency and type of question asked (Van der Meij, 1990). In contrast, when I correlated question-asking frequency (i.e., selection) in the experiment with question-asking frequency in the classroom, I found a low, but significant, correlation $(r=.28, p<.05)$.

The selection procedure is not in itself a bad method. It seems, for example, a practical way of gaining insight into the processes involved in question posing without having to bother with issues of question raising (i. e., generating). In addition, it bypasses the hard problem of the immediate categorization of the questions and of choosing the right answer during the experiment (Flammer, 1986). However, it does have at least one serious drawback: it is very difficult to settle upon the right kinds of question for the exper- 
iment. Unfortunately, researchers often cannot use questions that naturally occur, because there are frequently not enough such questions, or because there is too little correspondence with the experimental task. Researchers have therefore generated experimental questions that resemble real questions. This resemblance is based upon two critical assumptions. First, each question is categorized into a particular class of questions. Second, each class of questions is believed to correspond closely to a particular question function. For example, Nelson-LeGall and Glor-Scheib (1985) classified some children's questions (e.g., "How do I solve $14 \times 3$ ?" and "Can you show me how to multiply fractions?") as requests for hints, and others (e. g., ,What is $14 \times 3$ ?" and "Can you tell me the answer?") as requests for answers. Each class of questions was believed to reflect a certain information-seeking function. The hints were considered a good measure of question-asking for the purpose of learning how to solve problems. The answers supposedly came from the child's intention to complete tasks without much personal involvement.

Discussions should arise about how to classify questions and about equating certain classes of questions with particular question functions. For example, many researchers have tended to concentrate on the informationseeking function of questions. In dense social settings, such as classrooms, this may be the wrong focus. In these settings questioning might primarily serve the social purpose of helping pupils to develop relationships, as the following example illustrates (Gumperz, 1981, pp. 18-19):

The black children tended to call the teacher or the aide to ask for help and even after an explanation they were often heard to comment "I can't do this" or "I don't know how to do this". All such sentences were pronounced with similar intonation contours, characterized by high pitch register, sustained tone, and vowel elongation on the last syllable. We . . asked a group of black judges whether they thought the children really didn't know or didn't want to cooperate. The judges agreed in saying what the children really mean to say in these cases is "Help me; I don't like to work alone".

Categorizing the questions as serving a particular kind of information-seeking or social function is also difficult (see Usunov, 1987). Should one use syntactical, semantic, or pragmatic considerations to categorize a question? And is it fair to assume a close correspondence between the expression, class, and function of a question? Researchers must come up with an answer to these questions regardless of whether they use a selection procedure or whether the subjects are free to generate their own questions.

\section{Shaping the exchange}

Laboratory studies on questioning always have to cope with the exchange between questioner and respondent. In these exchanges there are problems with timing, norm-setting, and the content of the response.

Timing is crucial in answering questions and, in general, respondents should answer questions promptly and not a very long time afterwards. In experiments on the effects of prior knowledge on questioning this is problematic, since direct responses may activate dormant prior knowledge. Moreover, the responses are likely to lead to a unique pattern of responses and follow-up questions for each subject and thereby seriously compromise comparability between subjects. Thus, if the experiment simulates a naturalistic question - response - processing of response type of interaction it becomes virtually impossible to analyze the effects of prior knowledge on questioning. To solve this problem researchers have handled the timing problem in the following ways: they have not answered the questions at all, or they have asked their subjects to pose or write down all of their questions before answering each individual one (e.g., Allwood, \& Eliasson, 1988; Flammer, Grob, Leuthardt, \& Lüthi, 1984; Miyake \& Norman, 1979). These solutions are unsatisfactory for a number of reasons. First, in the absence of direct responses, questioners are unlikely to be concerned with communicating their precise informational needs. They need not create a common ground. The effect may be an abundance of questions that are difficult to interpret. Second, the subjects probably become more selective in what they ask and they are more likely to keep their questions to themselves. When this leads to an increase in internal questioning, the validity of the study is seriously affected. Third, since the subjects cannot base their questions upon responses to previous questions, they are severely limited in following a plan of action; they simply cannot follow a strategy in which questions and responses are integrated. Instead, they must revert to a strategy of asking as many questions as possible, only finding out later that a number of these questions were useless in view of the answers received to previous critical questions.

All experiments follow the Gricean principle of cooperation. That is, the norms are set in favor of questionasking, and social constraints are minimized, to give subjects maximal freedom to express questions as they arise. In addition to removing obstructing conditions, the instructions often explicitly encourage subjects to ask questions. In short, question-asking is not merely enabled, it is clearly stimulated by the instructions (e.g., Allwood, \& Eliasson, 1988; Fishbein, Eckart, Lauver, Van Leeuwen, \& Langmeyer, 1990; Flammer, Kaiser, \& Lüthi, 1981 a; Flammer, Kaiser, \& Müller-Bouquet, 1981b). How will this affect question-asking? I speculate that these procedures increase the chances that some subjects make up questions to please the experimenter. In contrast, other subjects may ask only a few questions because they still feel a little uneasy about taking the floor while someone they think superior - the experimenter - is present (see Dillon, 1990; Mishler, 1978) or because they do not believe that the conditions for question-asking are biased in their favor (there are ambiguous signs, since timing is not arranged for their convenience).

Another problematic part of the exchange lies in answering. How should one determine the content of the response? For example, what should one do with questions that are based on a false presupposition, as in the famous question "Have you stopped beating your wife?" And how should one respond to open questions such as "What do I have to do?" In all studies the researchers must have formulated some rules of conduct. However, only Flammer and his co-workers have described these rules in detail (see Flammer et al. 1981 a). According to Flammer, respon- 
dents require knowledge about the following factors. First, they need domain or task-specific knowledge. Second, they must know how to classify the questions. Third, they must have a set of principles for selecting the right response. In his experiments, especially in the later ones, Flammer worked hard to standardize these factors. So he began by drawing a very detailed chart of the experimental task (i.e., preparing a mousse au chocolat) and presented this chart to the respondents, who then all had the same task-specific knowledge. Next, he categorized the domain into a number of classes (e. g., goals, actions, criteria for success, ingredients, and instruments). For each domain class he further specified the kinds of question into types (e.g., yes/no, global/specific, one step/more steps) and coupled each to a specific answer rule. So, if an experimental subject asked a question such as "What do I use here?" all the respondents would classify it as an instrumental question of a global nature. Following the prescribed response rule, they would answer "A rod." Unfortunately, this important information is left out of the article published on the experiment (Flammer et al., 1984). Later, Flammer (1986) was to argue that he found himself entangled in issues concerning question answering rather than in the question-asking in which he was interested. He finds himself in good company with researchers in artificial-intelligence research (e.g., Lehnert, 1978), in philosophical research (e.g., Harrah, 1984), and in communication research (see Dillon, 1990), who all address answering. In contrast, most of the empirical studies on questioning do not describe the behavior of the respondents, or the response rules upon which it is based (e.g., Fishbein et al., 1990; Smith, Tykodi, \& Mynatt, 1988). This is a serious omission. Without this information the findings are virtually worthless because it is hard to imagine what interactions have taken place.

\section{Enabling other information-seeking strategies}

A third problem in experimental research on questioning is that one would like to have subjects use their full range of information-seeking strategies in dealing with the problem at hand and not just question posing. Normally there are lots of ways of gaining information besides question posing. For example, people can consult study-guides, dictionaries, encyclopedias, and other written materials, or they can touch or observe certain phenomena. Moreover, they can reflect upon an issue for a long time without ever expressing a question. Posing a question to a respondent is thus but one of many ways in which people search for information. In most experiments, however, besides guessing and inferencing, the subjects can only ask questions to find things out. Clearly, there are good reasons why other inquiry behaviors are minimized. Since the obstacles to asking questions are quite strong, researchers sometimes cannot do otherwise but stimulate them by invitation. Also, it is often tacitly assumed that the questions expressed in the experiments reflect (a wide range of) the questions that underly other inquiry behaviors. Thus, if someone, say, consults a document, it is presumed that the person has a question in mind for which he or she seeks an answer in the document. However, some questions are just too idiosyncratic, or ill formed, so that respondents cannot be expected to give helpful answers. In such cases people are likely to use other inquiry behaviors than expressing a question. More generally, then, since the studies focus on expressed questions, they reveal nothing of a person's internal questioning, or of the relationships of question-asking to other kinds of inquiry behavior.

\section{Conclusion}

Experimental research on questioning has not given enough attention to using the right kinds of question, to following an exchange that allows for prompt, standardized responses, and to having additional options for information-gathering strategies. The problems that these concerns pose cannot be solved overnight, but some suggestions can be given. First, researchers must insist on reporting these matters within their article. Especially on the issue of answering, they should not give way to editors who might want to nibble away here because of limited space. Second, researchers ought to seek additional support for the findings of their experiments. For example, they might want to compare the behavior of the subjects in the experiment with their behavior in a natural setting; they might want to consider using a direct approach to measuring the effects of someone's goal orientation on question-asking in addition to an indirect one; and they might want to try to conduct their experiment within a natural setting. Third, researchers might consider using more often a within-subjects design that allows them to study questioning on repeated occasions within the same domain of study. Such a design could also enable them to study how people sequence their questions (see Van der Meij, 1990). Fourth, researchers should consider following an interdisciplinary approach, either by making the research a team effort, or by expanding their own expertise. Such efforts will not only improve the methodological qualities of the research, but also contribute important insights to our understanding of questioning.

\section{References}

Allwood, C. M., \& Eliasson, M. (1988). Question asking when learning a text-editing system. International Joumal of Man-Machine Studies, 29, 63-79.

Dillon, J. T. (1990). The practice of questioning. New York: Routledge.

Fishbein, H. D., Eckart, T., Lauver, E., Van Leeuwen, R., \& Langmeyer, D. (1990). Learner's questions and comprehension in a tutorial setting. Journal of Educational Psychology, 82, 163-170.

Flammer, A. (1986). Asking a question: Which one - if any? Paper presented at the Memphis conference on Question Generation. Memphis, Tennessee.

Flammer, A., Kaiser, H., \& Lüthi, R. (1981 a). Gewusst Wie - Gefragt Wie (Internal Report No. 27). Fribourg: University of Fribourg.

Flammer, A., Kaiser, H. R., \& Müller-Bouquet, P. (1981 b). Predicting what questions people ask. Psychological Research, 43, 421-429.

Flammer, A., Grob, A., Leuthardt, T., \& Lüthi, R. (1984). Asking how to act. Archives de Psychologie, 52, 103-120.

Gumperz, J. J. (1981). Conversational inference. In J. Green \& C. Wallet (Eds.), Ethnography and language in educational settings. Norwood, N. J.: Ablex. 
Harrah, D. (1984). The logic of questions. In D. Gabbay \& F. Guentner (Eds.), Handbook of philosophical logic (Vol. II, pp. 715-764). Dordrecht: Reidel Publishing.

Lehnert, W. G. (1978). The process of question answering: A computer simulation of cognition. Hillsdale, $\mathrm{NJ}$ : Erlbaum.

Mishler, E. G. (1978). Studies in dialogue and discourse III: Utterance structure and utterance function in interrogative sequences. Journal of Psycholinguistic Research, 7, 279-305.

Miyake, N., \& Norman, D. A. (1979). To ask a question one must know enough to know what is not known. Journal of Verbal Learning and Verbal Behavior, 18, 357-364.

Nelson-LeGall, S., \& Glor-Scheib, S. (1985). Help-seeking in elementary classrooms: An observational study. Contemporary Educational Psychology, 10, 58-71.

Smith, K. H., Tykodi, T. A., \& Mynatt, B. T. (1988). Can we predict the form and function of spontaneous questions? Questioning Exchange, $2,53-60$.
Snyder, M. (1981). Seek and ye shall find: Testing hypotheses about other people. In E. T. Higgins, D. C. Herman, \& M. P. Zanna (Eds.), Social cognition: The Ontario symposium on personality and social psychology (Vol. 1, pp. 277-303). Hillsdale, NJ: Erlbaum.

Snyder, M., \& Swann, W. B. (1978). Hypothesis-testing processes in social interaction. Joumal of Personality and Social Psychology, 36, $1202-1212$.

Trope, Y., \& Bassok., M. (1983). Information-gathering strategies in hypothesis-testing. Journal of Experimental Social Psychology, 19, $560-576$.

Usunov, J. (1987). A functional aproach to questioning. Unpublished manuscript (available from J. Usunov, 28 Komi Street, 4003 Plovdiv, Bulgaria).

Van der Meij, H. (1990). Question asking: To know that you do not know is not enough. Journal of Educational Psychology, 82, $505-512$. 